\title{
PENGARUH KUALITAS PELAYANAN, DAYA SAING DESTINASI DAN PENGALAMAN SEBELUMNYA TERHADAP KEPUTUSAN BERKUNJUNG KEMBALI DENGAN KEPUASAN PENGUNJUNG SEBAGAI VARIABEL INTERVENING
}

\author{
Alvira Zulva Pallefi, Widiartanto \\ Administrasi Bisnis, Universitas Diponegoro, Indonesia \\ Email: alvirazulvapallefi@gmail.com
}

\begin{abstract}
The aim of this study is to measure the influence of service quality, destination competitiveness, and previous experience toward revisit decision trough tourist satisfaction. The population of this resarch is visitors of Goa Kreo, while the sample is 100 visitor of Goa Kreo with some certain prerequirements. The data was analyzed using two-step analysis with SPSS 17.0 for windows where the validity test, reliability test,doefficient of correlation, coefficient of determination, test of significance ( $t$-test and $f$ test) in advance has been done before.

The result of this study is showing that service quality, destination competitiveness and previous experience has positive impact toward visitor satisfaction, where the biggest impact is own by previous experience. Based on the result of two-step analysis, tourist satisfaction is an intervening variable toward revisit decision in this study.

Some recomendations are added based on those result. It's recomended that hygine, security, and hospitality in Goa Kreo must be incerased. Moreover, it's neccesary to increase destination competitiveness like facility's maintenance and added up some general facility so that visitor will be satisfied with their experiences and willing to come back to Goa Kreo.

Tujuan dilakukanya penelitian ini adalah untuk mengetahui pengaruh antara kualitas pelayanan, daya saing destinasi dan pengalaman sebelumnya terhadap keputusan berkunjung kembali melalui kepuasan pengunjung. Populasinya adalah seluruh pengunjung Goa Kreo, sedangkan sampelnya adalah 100 pengunjung Goa Kreo dengan kriteria tertentu.penelitian dilakukan di Objek Wisata Goa Kreo. Analisis yang digunakan dalam penelitian ini adalah analisis dua tahap menggunakan software SPSS 17.0 for Windows, di mana sebelumnya dilakukan uji validitas, uji reliabilitas, uji koefisien korelasi, koefisien determinasi, analisis regresi sederha dan berganda dan uji signifikasi (uji t dan uji F) terlebih dahulu.

Hasil penelitian ini menunjukan bahwa kualitas pelayanan, daya saing destinasi dan pengalaman sebelumnya berpengaruh secara parsial dan bersama-sama terhadap kepuasan pengunjung, dimana ketika bersama-sama pengalaman sebelumnya memiliki pengaruh yang paling besar terhadap kepuasan pengunjung. Berdasarkan hasil analisisi dua tahap kepuasan pengunjung merupakan variabel intervening terhadap keputusan berkunjung kembali dalam penelitian ini.

Berdasarkan hasil tersebut maka disarankan agar Goa Kreo meningkatkan kebersihan, keamanan dan keramahan pegawai sehingga tanggapan pengunjung mengenai kualitas pelayanan baik, selain itu perlu meningkatkan daya saing destinasi seperti perawatan fasilitas dan pengadaan fasilitas umum yang belum ada sehingga pengunjung puas dengan pengalaman berkunjungnya dan bersedia untuk berkunjung kembali di Goa Kreo.
\end{abstract}

\section{Keywords}

Service quality, Destination competitiveness, Previous experience, Tourist satisfaction and revisit decision

Kualitas layanan, daya saing tujuan, pengalaman sebelumnya, kepuasan wisatawan dan Keputusan

Kembali

\section{Pendahuluan}

Sektor pariwisata didefinisikan sebagai industri yang dihubungan dengan waktu luang dan perjalanan dan dipercaya sebagai satu dari banyak sektor yang berkembang di dunia dan berkontribusi pada pertumbuhan ekonomi suatu negara dan juga memberikan keuntungan ekonomi kepada daerah (Chee-Hua, MayChiun, Songan, Nair, 2014). 
Sebagai salah satu wisata alam Goa Kreo memiliki peranan sebagai konservasi secara umum dan memberikan kontribusi pada sektor ekonomi dan pembangunan daerah dengan membuka peluang kerja baru dan berperan aktif pada pengembangan daerah sekitar. Output dari destinasi wisata Goa Kreo adalah jumlah pengunjung, Sehingga apabila keunggulan destinasi wisata semakin meningkat, output pengunjung juga akan meningkat sesuai dengan target atau bahkan melebihi target yang diharapkan.

Tingkat wisatawan yang berkunjung merupakan salah satu indikator, apakah sebuah destinasi wisata dinilai berhasil atau tidak, apakah sebuah destinasi wisata memiliki keunggulan yang dapat bersaing, pelayanan yang prima, fasilitas yang memadai dan sebagainya. Maka dari itu penting untuk menarik minat wisatawan untuk berkunjung ke sebuah objek wisata.

Kepuasan pengunjung diduga menjadi salah satu faktor yang cukup mempengaruhi keputusan berkunjung atau berkunjung kembali ke sebuah tempat wisata. beberapa hal berikut ini diduga mempengaruhi kepuasan pengunjung, diantaranya adalah kualitas pelayanan, daya saing destinasi dan pengalaman sebelumnya. Perlu dilakukan strategi yang tepat guna mencapai tujuan untuk meningkatkan pengunjung di Goa Kreo terkait dengan hal-hal yang telah disebutkan di atas.

\section{Kajian Teori}

\section{Kualitas Pelayanan}

Menurut Tjiptono dan Chandra (2005 : 121) Kualitas layanan (service quality) sebagai ukuran seberapa bagus tingkat layanan yang diberikan mampu sesuai dengan ekspektasi pelanggan. Untuk mengukur baik buruknya kualitas pelayanan digunakan indikator berupa accessibility \& logistic, core tourism experience, kebersihan, informasi, keamanan, dan hospitality.

\section{Daya Saing Destinasi}

Menurut D'Hauteserre (2000), daya saing destinasi merupakan kemampuan destinasi untuk menarik pengunjung untuk mengunjungi atau mengunjungi kembali atau bisa juga disebut mempertahankan market position dan perubahan destinasi sesuai zaman. Untuk mengukur baik atau buruknya daya saing destinasi digunakan indikator sumber daya manusia, budaya, dan alam, legal framework, business environtmenr \&infrastructure

\section{Kepuasan Pengunjung}

Kepuasan adalah tingkat perasaan seseorang setelah membandingkan kinerja/hasil yang dirasakan dengan harapan (Oliver dalam Supranto, 2006: 233). Untuk mengukur kepuasan pengunjung digunakan indikator sebagai berikut, kepuasan pelanggan keseluruhan (Overal Customer Satisfaction), dimensi kepuasan pelanggan, konfirmasi harapan, dan kesediaan untuk merekomendasi.

\section{Keputusan berkunjung kembali}

Pembelian ulang adalah kegiatan pembelian yang dilakukan lebih dari satu kali atau beberapa kali. (Peter dan Olson, 2000). Untuk mengukur keputusan berkunjung kembali pengunjung Goa Kreo digunakan keinginan kuat untuk membawa keluarga ke destinasi wisata, memiliki keinginan sendiri untuk kembali mengunjungi destinasi wisata dan menjadikan destinasi wisata sebagai pilihan utama.

\section{Pengalaman Sebelumnya}

Experiential Marketing merupakan pendekatan pemasaran yang melibatkan emosi dan perasaan konsumen dengan 
menciptakan pengalaman-pengalaman positif yang tidak terlupakan sehingga konsumen mengkonsumsi dan fanatik teradap produk tertentu. (Schmitt, 1990:60) untuk mengukur kepuasan pada pengalaman sebelumnya digunakan indikator sebagai berikut sense, feel, dan think.

\section{Hipotesis Peneilitian}

Hipotesis merupakan jawaban sementara atas rumusan masalah penelitian, dikatakan sementara karena jawaban yang dierikan baru didasarkan teori-teori yang relevan, belum didasarkan pada fakto empiris yang diperoleh melalui pengumpulan data d lapangan. Berdasarkan perumusan masalah yang dibuat hipotesis sebagi berikut:

a. H1 diduga ada pengaruh antara kualitas pelayanan (X1) terhadap kepuasan pengunjung (X4)

b. H2 diduga ada pengaruh antara daya saing destinasi (X2) terhadap kepuasan pengunjung (X4)

c. H3 diduga ada pengaruh antara pengalaman sebelumnya (X3) terhadap kepuasan pengunjung (X4)

d. H4 Diduga ada pengaruh antara kualitas pelayanan (X1), daya saing destinasi (X2), dan pengalaman sebelumnya (X3) terhadap kepuasan pengunjung $(\mathrm{Z})$.

e. H5 diduga ada pengaruh antara kepuasan berkunjung (X4) terhadap keputusan berkunjung kembali (Y)

\section{Metodologi Penelitian}

Penelitian ini menggunakan tipetipe penelitian explanatory research yaitu penelitian yang bermaksud menyoroti hubungan variabel-variabel penelitian kemudian menguji hipotesis yang telah dirumuskan sebelumnya. Populasi yang digunakan dalam penelitian ini adalah semua pengunjung yang mengunjungi Goa Kreo dan belum diketahui jumlahnya. Sampel pada penelitian ini merupakan 100 orang dari Pengunjung Goa Kreo dengan kriteria yang telah ditentukan.

Metode analisis data yang dilakukan adalah uji validitas, uji reliabilitas, koefisien korlelasi, koefisien determinasi, analisis regresi sederhana, analisis regresi berganda, uji signifikasi (uji t dan uji f) dan analisa dua tahap dengan menggunakan software spss ver 17.00.

\section{Pembahasan}

Berdasarkan penelitian yang dilakukan, kualitas pelayanan memiliki pengaruh terhadap kepuasan pengunjung dengan taraf signifikansi $5 \%$ atau 0,05 maka diperoleh nilai t sebesar 1,9845 di mana $\mathrm{t}$ hitung $(8,560)>\mathrm{t}$ tabel $(1,9845)$ sehingga hipotesis 1 "terdapat pengaruh antara kualitas pelayanan terhadap kepuasan pengunjung" diterima. Nilai koefisien determinasi yang diperoleh adalah 0,428 atau $42,8 \%$. Hal ini menunjukan bahwa variabel kepuasan pengunjung dapat dijelaskan oleh variabel kualitas pelayan sebanyak $42,8 \%$ sedangkan sisanya $(100 \%-42,8 \%=$ $57,2 \%$ ) dijelaskan oleh faktor selain kualitas pelayanan.

Berdasarkan penelitian kali ini, daya saing destinasi memiliki pengaruh terhadap kepuasan pengunjung dengan taraf signifikansi $5 \%$ atau 0,05 maka diperoleh nilai $\mathrm{t}$ sebesar 1,9845 di mana $\mathrm{t}$ hitung $(8,790)>\mathrm{t}$ tabel $(1,9845)$ sehingga hipotesis 2 "terdapat pengaruh antara daya saing destinasi terhadap kepuasan pengunjung" diterima. Nilai koefisien determinasi yang diperoleh adalah 0,441 atau $44,1 \%$. Hal ini menunjukan bahwa variabel kepuasan pengunjung dapat dijelaskan oleh variabel kualitas pelayan sebanyak $44,1 \%$ sedangkan sisanya $(100 \%-44,1 \%=55,9 \%)$ dijelaskan oleh faktor selain daya saing destinasi. 
Berdasarkan penelitian terhadap penngaruh pengalaman sebelumnya terhadap kepuasan pengunjung dan melalui penelitian yang telah dilakukan dapat diketahui bahwa pengalaman sebelumnya memiliki pengaruh terhadap kepuasan pengunjung dengan taraf signifikansi $5 \%$ atau 0,05 maka diperoleh nilai $\mathrm{t}$ sebesar 1,9845 di mana $\mathrm{t}$ hitung $(9,329)>t$ tabel $(1,9845)$ sehingga hipotesis 3 "terdapat pengaruh antara pengalaman sebelumnya terhadap kepuasan pengunjung" diterima. Nilai koefisien determinasi yang diperoleh adalah 0,470 atau $47,0 \%$. Hal ini menunjukan bahwa variabel kepuasan pengunjung dapat dijelaskan oleh variabel pengalaman sebelumnya sebanyak $47,0 \%$ sedangkan sisanya $(100 \%-47,0 \%=53 \%)$ dijelaskan oleh faktor selain pengalaman sebelumnya.

Hipotesos ke empat mengatakan bahwa kualitas pelayanan, daya saing destinasi dan pengalaman sebelumnya berpengaruh terhadap kepuasan pengunjung. Berdasarkan penelitian kali ini, kualitas pelayanan, daya saing destinasi dan pengalaman sebelumnya memiliki pengaruh terhadap kepuasan pengunjung dengan taraf signifikansi $5 \%$ atau 0,05 maka diperoleh $\mathrm{F}$ tabel sebebesar 2,47 di mana $F$ hitung $(48,896)$ $>\mathrm{F}$ tabel $(2,47)$ sehingga hipotesis 4 "terdapat pengaruh antara kualitas pelayanan, daya saing destinasi dan pengalaman sebelumnya terhadap kepuasan pengunjung" diterima. Nilai koefisien determinasi yang diperoleh adalah 0,592 atau 59,2\%. Hal ini menunjukan bahwa variabel kepuasan pengunjung dapat dijelaskan oleh variabel kualitas pelayan sebanyak 59,2\%, sedangkan sisanya $(100 \%-59,2 \%=$ $40,8 \%$ ) dijelaskan oleh faktor selain kualitas pelayanan, daya saing destinasi dan pengalaman sebelumnya. Sehingga hipotesis ke 4 yang menyatakan bahwa "kualitas pelayanan, daya saing destinasi dan pengalaman sebelumnya memiliki pengaruh terhadap kepuasan pengunjung" diterima.

Hipotesis ke lima menunjukan bahwa kepuasan pengunjung berpengaruh terhadap keputusan berkunjung kembali.Berdasarkan penelitian pengaruh kepuasan pengunjung terhadap keputusan berkunjung kembali dan berdasarkan penelitian yang dilakukan kepuasan pengunjung memiliki pengaruh terhadap keputusan berkunjung kembali dengan taraf signifikansi $5 \%$ atau 0,05 maka diperoleh $\mathrm{t}$ tabel sebebesar 1,9845 di mana $t$ hitung $(9,837)>\mathrm{t}$ tabel $(1,9845)$ sehingga hipotesis 5 "terdapat pengaruh kepuasan pengunjung terhadap keputusan berkunjung kembali"diterima. Nilai koefisien determinasi yang diperoleh adalah 0,497 atau 49,7\%. Hal ini menunjukan bahwa variabel keputusan berkunjung kembali dapat dijelaskan oleh variabel kualitas pelayan sebanyak 49,7\%. Sedangkan sisanya $(100 \%-49,7 \%=$ $50,3 \%$ ) dijelaskan oleh faktor selain kepuasan pengunjung.

Berdasarkan uji regresi dua tahap yang dilakukan didapatkan kesimpulan bahwa variabel kepuasan pengunjung adalah variabel intervening untuk variabel

\section{Kesimpulan dan Saran}

\section{Kesimpulan}

Berdasarkan penelitian yang pernah dilakukan, kualitas pelayanan yang ada di Goa Kreo baik karena sebesar 52\% dari responden menyatakan bahwa, kualitas pelayanan di Goa Kreo baik. hal ini dibuktikan dengan positifnya penilaian responden terhadap kemudahan akses jalan dan kelayakan akses jalan yang memudahkan pengunjung untuk menempuh perjalanan menuju Goa Kreo, serta keindahan alam yang masih terjaga di Goa Kreo. Akan tetapi masih ada beberapa aspek yang tidak mencapai nilai rata-rata yaitu indikator kebersihan, 
keamanan, keramahan dan kelengkapan informasi.

Berdasarkan penelitian yang pernah dilakukan, Daya Saing Destinasi yang ada di Goa Kreo baik karena sebesar $49 \%$ dari responden menyatakan bahwa kondisi alam, keunikan, keragaman yang menarik, aturan dan tata tertib, kelengkapan fasilitas dan harga tiket masuk di Goa Kreo yang cukup terjangkau menghasilkan tanggpan positif dari responden akan tetapi masih ada beberapa indikator yang dinilai belum memenuhi nilai rata-rata indikator yaitu indikator kondisi satwa yang kurang terawat, kelayakan fasilitas yang ada, jarak dengan fasilitas umum yang masih jauh, harga akeses (transport) yang relatif mahal dan harga makanan dan minuman yang kurang terjangkau di Goa kreo.

Berdasarkan penelitian yang pernah dilakukan, pengalaman sebelumnya yang ada di Goa Kreo puas karena sebesar $46 \%$ dari responden menyatakan bahwa mereka tertarik kepada acara-acara yang diselenggarakan di Goa Kreo. Sedangkan masih ada beberapa indikator yang belum memenuhi nilai rata-rata indikator yaitu ketertarikan kepada objek wisata Goa Kreo, kenyamanan ketika berkunjung ke Goa Kreo, dan perencanaan sebelum mengunjungi Goa Kreo.

Berdasarkan penelitian yang pernah dilakukan, kepuasan pengunjung yang ada di Goa Kreo meuaskan karena sebesar $41 \%$ dari responden menyatakanbahwa mereka puas dengan kunjungan yang sebelumnya pernah dilakukan. Hal ini berarti $41 \%$ dari responden merasa puas, hal ini terlihat melalui respon positif terhadap indikator kepuasan yaitu ketersediaan untuk merekomendasikan Goa Kreo kepada orang lain, kepuasan secara menyeluruh, kepuasan terhadap keragaman wisata Goa Kreo, dan kesesuaian antara harapan dan kenyataan ketika berkunjung ke lokasi. Akan tetapi terdapat indikator yang tidak memenuhi rata-rata nilai indikator yaitu ketidakpuasan pengunjung.

Berdasarkan penelitian yang pernah dilakukan, keputusan berkunjung kembali yang ada di Goa Kreo baik karena sebesar 63\%. Hal ini berarti 63 responden menyatakann bahwa mereka setuju untuk berkunjung kembali ke Goa Kreo dan mengajak serta kerabat atau orang-orang terdekat untuk berkunjung ke Goa Kreo. Akan tetapi terdapat indikator yang tidak memenuhi nilai rata-rata indikator yaitu indikator menjadikan Goa Kreo sebagai prioritas utama mereka.

Variabel kualitas pelayanan memiliki pengaruh positif terhadap kepuasan berkunjung. Hal ini berati semakin meningkatnya kualitas pelayanan akan meningkatkan pula kepuasan berkunjung dari wisatawan.

Variabel daya saing destinasi memiliki pengaruh positif terhadap kepuasan berkunjung. Hal ini berati semakin meningkatnya daya saing destinasi akan meningkatkan pula kepuasan berkunjung dari wisatawan.

Variabel pengalaman sebelumnya memiliki pengaruh positif terhadap kepuasan berkunjung. Hal ini berati semakin meningkatnya pengalaman sebelumnya akan meningkatkan pula kepuasan berkunjung dari wisatawan.

Variabel kualitas pelayanan, daya saing destinasi, dan pengalaman sebelumnya bersama-sama memiliki pengaruh positif terhadap kepuasan berkunjung, dimana penglaman sebelumnya memiliki pengaruh paling besar dibandingkan dengan kualitas pelayanan dan daya saing destinasi.

1. Variabel kepuasan pengunjung memiliki pengaruh positif terhadap keputusan berkunjung kembali. Hal ini berati semakin meningkatnya 
kepuasan berkunjung akan meningkatkan pula keputusan berkunjung kembali dari wisatawan.

2. Variabel kualitas pelayanan, daya saing destinasi, pengalaman sebelumnya dan kepuasan pengunjung bersama-sama memiliki pengaruh positif terhadap keputusan berkunjung kembali, dimana kepuasan pengunjung memiliki pengaruh paling besar dibandingkan dengan kualitas pelayanan, daya saing destinasi dan pengalaman sebelumnya.

3. Tingginya pengaruh pengalaman sebelumnya terhadap kepuasan pengunjung, dan tingginya pengaruh kepuasan pengunjung terhadap keputusan berkunjung kembali, maka dapat disimpulkan bahwa apabila pada pengalaman sebelumnya wisatawan mendapatkan pengalaman yang berkesan dan positif maka dapat menunjang kepuasan pengunjung, dan kepuasan pengunjung yang tinggi dapat mempengaruhi keputusan berkunjung kembali.

\section{Saran}

Penulis menyarankan agar pihak pengelola Goa Kreo dapat meningkatkan kualitas pelayanan dengan (1) meningkatkan intensitas dan menambah titik-titik untuk dibersihkan, (2) menambah keamanan untuk membantu pengunjung di dalam Goa Kreo (3) menegaskan bahwa pengunjung itu penting bagi destinasi wisata untuk meningkatkan keramahan.

Kemudian meningkatkan daya saing destinasi dengan (1) melakukan perawatan rutin fasilitas yang disediakan (2) mengusulkan agar dibuat fasilitas umum seperti ATM (3) mengusulkan jalur BRT baru untuk Goa Kreo.
Sedangkan untuk pengalaman sebelumnya, (1) meningkatkan promosi acara-acara rutin tahunan. Untuk meningkatkan kepuasan pengunjung dapat dilakukan dengan berinovasi wahan baru untuk Goa Kreo dengan memanfaatkan potensi waduk yang dimiliki oleh Goa Kreo, misalnya dengan menambah wahana baru banana boat, wisata perahu, lomba memancing dan lainya.

\section{Daftar Referensi}

Che-Hua, Chin, May-Chiun, Lo, Peter Songan, Vikneswaran Nair. 2014. Rural Tourism Destination Competitiveness: A Study on Annah Rais Longhouse Homestay, Sarawak. Jurnal Elsevier.

Deasy Wulandari, Ari Subagio. 2015. Consumer Decision Making in Conventional Banks and Islamic Bank based on Quality of Service Perception. Jurnal Elsevier.

Hasan, Ali. 2013. Marketing dan Kasus Kasus Pilihan. Yogyakarta: Center for academic publishing service.

I Gusti Ayu Eka Suwintari. 2012. Kepuasan Wisatawan Terhadap Kualitas Pelayanan "Tourist Information Counters" Di Jalan Padma Utara Legian, Kuta. Tesis. Universitas Udayana.

Kotler, Philip. 1997. Manajemen Pemasaran.Jakarta: Perhallindo

Sutisna. Perilaku Konsumen \& Komunikasi Pemasarn. 2000. Bandung: PT. REMAJA ROSDAKARYA.

Peter, J Paul, dam Jerry C. Olson, 2000.Consumer Behaviour perilaku konsumen dan strategi pemasaran dan strategi pemasaran edisi keempat. Jakarta: Penerbit Erlangga. 
Schmitt.1999. Experiental Marketing: How to Get Your Customer to Sense, Feel, Think, Act, Relate to Your Company and Branda. New York:Free Pass.

Sedarmayanti. 2014. Kebudayaan \& Industri Pariwisata, Bandung: PT. Refika Aditama.

Siti Daleela Mohd Wahid, Nor Khasimah Aliman, Shareena Mohamed Hashim, Syahmi Harudin. 2015. First-time and Repeat Visitors to Langkawi Island, Malaysia. Jurnal Elsevier.

Sushila Devi Rajaratnam, Uma Thevi Munikrishnan, Seed Pahlevan Sharif \& Vikneswaran Nair. 2014. Service Quality and Previous Experience as Moderator in Determining Tourist' Satisfaction with Rural Tourism Destination in Malaysia: A Partial Least Square Approach. Jurnal Elsevier.

Tjiptono, Fandy. 1998. Manajemen Jasa. Yogyakarta: C.V Andi Offset. 2000. Manajemen Jasa. Yogyakarta: C.V Andi Offset.

\footnotetext{
- 2004. Strategi

Pemasaran. Yogyakarta: C.V Andi Offset.
}

Ebru Tümer Kabaday, Alev Koçak Alan. 2012. Revisit Intention of Consumer Electronics Retailers: Effects of Customers' Emotion, Technology Orientation and WOM Influence. Jurnal Elsevier.

Faruk Alaeddinoglu \& Ali Selcuk Can. 2011. Identification and classification of nature-based tourism resources: western Lake Van basin, Turkey. Jurnal Elsevier Tjiptono, Fandy, Gregorius Chandra. 2005. Manajemen Kualitas Jasa. Yogyakarta:ANDI.

Cristea, Stefan Dragos. Travel \& Tourism Competitiveness: a study of world's top economic competitive countries. Jurnal Elsevier. 
